Research Article

\title{
Seismic Response of Rock Slopes with the Anchor Cable in Centrifuge Modeling Tests
}

\author{
Yong Nie, ${ }^{1}$ Yufei Zhao $\left(\mathbb{D},{ }^{1}\right.$ Xiaogang Wang, ${ }^{1}$ Linhao $\mathrm{Li}^{2}{ }^{2}$ and Hongtao Zhang ${ }^{3}$ \\ ${ }^{1}$ State Key Laboratory of Simulation and Regulation of Water Cycle in River Basin, \\ China Institute of Water Resources and Hydropower Research (IWHR), Beijing 100048, China \\ ${ }^{2}$ AVIC Institute of Geotechnical Engineering Co., Ltd., Beijing 100098, China \\ ${ }^{3}$ College of Civil Engineering, North China University of Technology, Beijing 100144, China \\ Correspondence should be addressed to Yufei Zhao; zhaoyf@iwhr.com
}

Received 27 February 2020; Revised 26 May 2020; Accepted 20 June 2020; Published 11 August 2020

Academic Editor: Chunshun Zhang

Copyright (c) 2020 Yong Nie et al. This is an open access article distributed under the Creative Commons Attribution License, which permits unrestricted use, distribution, and reproduction in any medium, provided the original work is properly cited.

\begin{abstract}
In order to study the seismic response of the rock slopes with the anchor cable, centrifuge modeling tests were performed on concrete slope models. Different seismic loadings were performed to investigate the horizontal acceleration response, the rock slope displacement, and the stress of anchor cables. The results show that the horizontal acceleration response is obviously amplified by a rock slope. Under the same conditions, the higher the seismic intensity is, the larger the acceleration amplification coefficient will be. Anchor cable can effectively reduce the acceleration amplification effect of the slope. For the slope with a structural plane, the anchor cable at the structural plane is stressed greatly during the seismic action, and the strength of anchor cables near the expected structural plane is important.
\end{abstract}

\section{Introduction}

Slope instability induced by earthquakes is one of the main secondary geological disasters, with the characteristics of wide distribution, large number, and great harm [1-5]. In such disasters, rock slope failure hazard with a large structural plane is the most common accident of actual geotechnical engineering in earthquakes, such as earthquakes in Wenchuan (2008) and Yushu (2010), where about 200,000 slope failures were triggered [6]. Some scholars believe that the geological structure characteristics will greatly affect the occurrence of landslide disaster under the condition of strong ground motion $[7,8]$.

At present, many scholars have done a lot of research on the rock slope dynamic response under earthquake load. Analyzing the dynamic response of the rock slope is an important way to study the failure mechanism, stability, and anchoring mechanism of the slope under earthquakes. The dynamic response of the slope includes acceleration, velocity, displacement, and stress state.
Through shaking table test, Fan et al. [9] studied the dynamic characteristics of slopes with different geological structures (bedding slope and counter-bedding slope). During the test, the dynamic characteristics of the two slopes have similarities and differences. For acceleration, the coefficient of acceleration increases with the elevation of the slope. Under the same conditions, the acceleration amplification effect of the bedding slope is significantly greater than that of the counter-bedding slope. Based on finite element modeling and measured data, Massey et al. [10] studied the seismic response of rock cliffs. Results show that the amplification of out-of-slope acceleration increases nonlinearly with the slope height. As each side of the slope has special material modulus and strength, the acceleration data were not smooth. In general, the amplification of shaking came to its maximum at the top of the slope.

In the conventional shaking table model test, the size of the model is reduced by $n$ times. If the model is made of prototype materials, according to similar conditions, the prototype stress is $n$ times of the model stress, which means 
that the model stress is not consistent with the prototype stress.

In this case, when the stress of the prototype exceeds the elastic limit of the material and enters plastic deformation, the model is still in the elastic stage. Therefore, the conventional shaking table test is only effective in the elastic range, and it is difficult to test the model in the plastic deformation stage, so it is not suitable for the research of destructive test.

In the centrifuge test, each point in the model is subjected to a centrifugal inertial force $n$ times greater than the Earth's gravitational acceleration, increasing the model's dead weight $n$ times. According to similar conditions, the stress of the centrifuge model is the same as that of the prototype. Therefore, the centrifuge model test is a "full true" model test equal to the prototype stress. In the test, the prototype material can be directly used to make the model, and the whole process of the mechanical model test can be carried out until the model is broken.

By centrifuge model test and numerical simulation, Zhang et al. $[11,12]$ studied the acceleration distribution of the layered slope (loess-mudstone). Overall, the acceleration increases as the height increases. In addition, by analyzing the data of the acceleration, it was found that the acceleration value in loess was much larger than that in mudstone. This is similar to some of Massey's ideas.

To study the seismic performance of the slope with a potential sliding surface, centrifuge model test is implemented. Since the late 1990s, many research studies on dynamic centrifuge modeling test have been carried out, and many research achievements about slope deformation and stability under seismic force have been made [12-16].

Under the earthquake load, the rock slope with weak structure surface is easy to produce instability failure. Many scholars believe that it is necessary to reinforce the slope mentioned above. Theory and experiments have been developing very quickly for the reinforced slope under dynamical response [17-21]. For an unstable slope with the potential sliding surface (structural surface), prestressed anchor cable is usually adopted. At present, the anchor cable design and construction methods mainly adopt the method of safety factor. The method does not consider the dynamic influence and the shear characteristics of the anchor cables, and there is no in-depth study on the dynamic response of the anchor cable structure. In previous studies, little research has been done on stress and deformation of the anchor body and its interplay with rock mass to understand its strengthening effect for a structural plane.

In this paper, the centrifugal model tests of different magnitudes at different acceleration levels are carried out by using the bidirectional independent shaking table. The dynamic characteristics of the rock slope are analyzed preliminarily. The strain of the anchor cable at different positions in the slope under the earthquake is studied. The dynamic response of the anchor cable under different seismic intensities and different centrifugal accelerations is studied. The research of this paper has laid a foundation for the following related research.

\section{Materials and Methods}

2.1. Testing Equipment and Model Box. The centrifuge modeling tests were performed on a large-scale geotechnical centrifuge, as shown in Figure 1. The geotechnical centrifuge is equipped with a bidirectional shaking table system that could produce horizontal and vertical vibrations independently. The geotechnical centrifuge can provide a maximum loading of $400 \mathrm{~Hz}$ and support up to $4400 \mathrm{~kg}$ models. The detail of the geotechnical centrifuge is shown in Table 1. The model box is made up of laminated aluminum alloy. Its internal length, width, and height are $750 \mathrm{~mm}, 350 \mathrm{~mm}$, and $520 \mathrm{~mm}$, respectively.

2.2. Similarity Laws and Materials. Using a centrifuge, the model can be tested under the same stress field as the prototype. Due to the change of gravity acceleration during the centrifuge experiment, in order to obtain the same dynamic response as the prototype, the relevant parameters (density, strength, modulus, etc.) of the model must be changed by dimensional analysis [12].

We define the ratio between the prototype value and the model value of the three control variables (size, density, and acceleration) in the model test as

$$
\begin{gathered}
\eta_{l}=\frac{L^{p}}{L^{m}} \\
\eta_{\rho}=\frac{\rho^{p}}{\rho^{m}} \\
\eta_{g}=\frac{g^{p}}{g^{m}} .
\end{gathered}
$$

According to the mechanical equilibrium condition, the following can be obtained:

$$
\eta_{\sigma}=\eta_{l} \eta_{\rho} \eta_{g}
$$

The most important objective of the centrifuge model test is to ensure that the stress of the prototype and the corresponding points of the model are equal, which is $\eta_{\sigma}=1$. In order to achieve this goal, the same material (or similar material) is chosen in centrifugal model experiments making the model, which is $\eta_{\rho}=1$. Then, the geometric size of the model is reduced to $1 / n n$ of the prototype, and the field acceleration (centrifugal acceleration) of the model is increased to $n$ times of the gravitational acceleration, which are $\eta_{l}=(1 / n)$ and $\eta_{g}=n$. Finally, $\eta_{\sigma}=1$ can be obtained, which ensures that every stress of the model is the same as that of the prototype, so as to achieve the purpose of using the model to represent the prototype.

Dynamic events (such as earthquake loading) require special consideration in order to define appropriate scaling laws. For such problems, it is simplest to consider the basic differential equation describing the cyclic motion $x_{\mathrm{p}}$ in the prototype [22]:

$$
x_{p}=a_{p} \sin \left(2 \pi f_{p} t_{p}\right),
$$




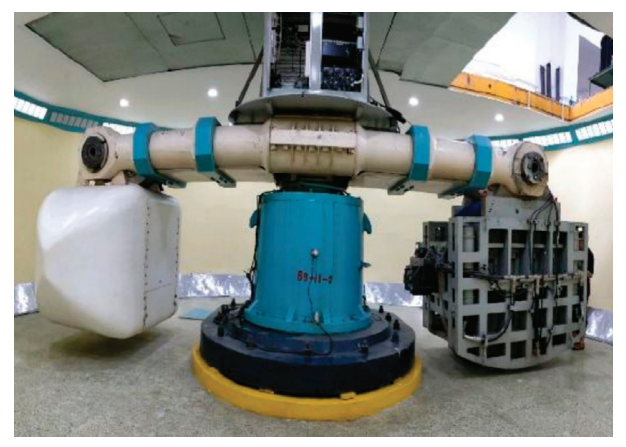

(a)

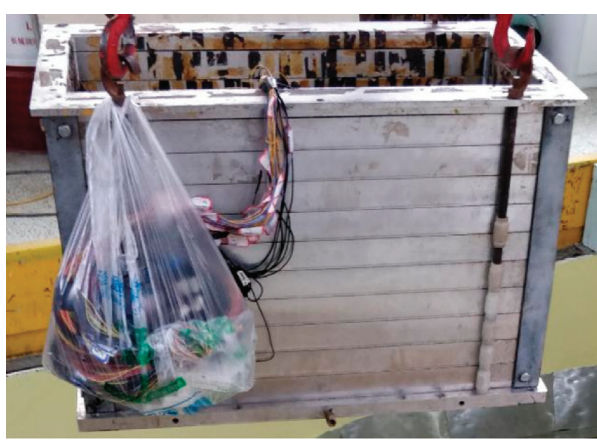

(b)

Figure 1: Centrifuge test system. (a) The large-scale geotechnical centrifuge. (b) The model box.

TABLE 1: Instrument indicators of the geotechnical centrifuge and the shaking table system.

\begin{tabular}{lc}
\hline Item & Index \\
\hline Acceleration of the centrifuge & $100 \mathrm{~g}$ \\
Direction and acceleration of & Horizontal-30 g/vertical- \\
vibrations & $20 \mathrm{~g}$ \\
Frequency of vibration & $400 \mathrm{~Hz}$ \\
Load & $4400 \mathrm{kN}$ \\
Shape of the vibration wave & Random \\
\hline
\end{tabular}

where $a_{p}$ is the amplitude of the motion of frequency $f_{p}$. Differentiating equation (3) gives

$$
\frac{d^{2} x_{p}}{d^{2} t_{p}}=-\left(2 \pi f_{p}\right)^{2} a_{p} \sin \left(2 \pi f_{p} t_{p}\right)
$$

where $\left(2 \pi f_{p}\right)^{2} a_{p}$ is the amplitude of acceleration magnitude.

Using an analogous expression for motion in the model, the amplitude of model acceleration magnitude can be derived to be $\left(2 \pi f_{m}\right)^{2} a_{m}$. In the model, linear dimensions and gravity acceleration have scale factors $1: n$ and $1: n^{-1}$, respectively, in order to retain similarity. From the above, it is clear that the model acceleration amplitude is $n$ times as much as the prototype acceleration amplitude.

In consideration of the limitation of testing condition, the index of the centrifuge, and the dimension of the model box, in order to simulate the seismic response of rock slopes with the anchor cable as much as possible, the accelerations of the centrifuge were designed to be $30 \mathrm{~g}$ and $40 \mathrm{~g}$ in the tests. According to certain accelerations, the similarity law of each parameter is shown in Table 2.

Considering the centrifuge models are used to simulate rock slopes with the anchor cable, materials for making models are divided into rock simulation and anchor cable simulation in this experiment.

In general, for in situ rock material, the compressive strength is 20 to $150 \mathrm{MPa}$, the volume weight is 24 to $27 \mathrm{kN} /$ $\mathrm{m}^{3}$, the elastic modulus is 10 to $70 \mathrm{GPa}$, the internal friction angle is $20^{\circ}$ to $50^{\circ}$, Poisson's ratio is 0.1 to 0.35 , and the cohesion is 1 to $50 \mathrm{MPa}$. According to the similar ratio analysis of this experiment, the rock simulative material of the model for the present study was formulated using a blend of common Portland cement (42.5), standard sand, and water in $1: 3: 1$ ratio. For the rock simulative material, experimental results show that the compressive strength is 4.5 MPa, the elastic modulus is $6.3 \mathrm{GPa}$, and the density is $2 \mathrm{~g} / \mathrm{cm}^{3}$. In consideration of the model scale and the bonding problem between the strain gauge and the anchor cable simulative material, copper sheets are used for simulating the anchor cable material. The copper sheet's section size is $1 \mathrm{~mm} \times 10 \mathrm{~mm}$, the elastic modulus is $108 \mathrm{GPa}$, Poisson's ratio is 0.32 , and the density is $8.9 \mathrm{~g} / \mathrm{cm}^{3}$.

2.3. Test Cases and Input Excitations. Centrifuge test model was made according to the size of the prototype Zipingpu reservoir slope and the model box of the centrifuge. The detailed dimensions of the model are shown in Figure 2(a); the inner fault surface of the slope was designed to be $40^{\circ}$, and the external slope surface was designed to be $75^{\circ}$. In the slope model, 6 anchor cables which are orthogonal to the structural plane are arranged. In this experiment, the models are made by layered casting techniques. In addition, in order to create the inner fault surface, some kraft paper is used in the process of model making in the experiment. The design drawing and object drawing of the model are shown in Figure 2(b).

Due to the limitation of the size of the model box, it is difficult to simulate the prototype structure as a whole when conducting large-scale geostructural model tests. For structures such as slopes and dams, the model can only simulate parts of the structure between two cross sections. In addition, in the dynamic test, seismic waves will be reflected at the boundary of the model box, causing adverse effects on the test. In the centrifuge test, the boundary effect mainly comes from the constraint effect of the sidewall of the model box on the model. In this test, in order to reduce the boundary effect, $20 \mathrm{~mm}$-thick soft material (polystyrene foam) was placed on the inner wall of both ends of the vibration direction of the model box. At the same time, four steel members were used to reinforce the model box and improve its rigidity [23].

The simplest wave is the simple harmonic, which is the basic composition of natural seismic waves. French physicist Fourier first quantified complex waves in 1822 as the sum of simple harmonics of various frequencies and amplitudes. 
TABLe 2: Similarity law in the centrifugal model test.

\begin{tabular}{lcccc}
\hline Physical values & Dimension & Unit & Model (30 g)/prototype (1 g) & Model (40 g)/prototype $(1 \mathrm{~g})$ \\
\hline Length (L) & $\mathrm{L}$ & $\mathrm{m}$ & $1 / 30$ & $1 / 40$ \\
Area (A) & $\mathrm{L}^{2}$ & $\mathrm{~m}^{2}$ & $1 / 30^{2}$ & $1 / 40^{2}$ \\
Volume (V) & $\mathrm{L}^{3}$ & $\mathrm{~m}^{3}$ & $1 / 30^{3}$ & $1 / 40^{3}$ \\
Quality (m) & $\mathrm{M}$ & $\mathrm{kg}$ & $1 / 30^{3}$ & $1 / 40^{3}$ \\
Acceleration (a) & $\mathrm{LT}^{-2}$ & $\mathrm{~m} / \mathrm{s}^{2}$ & 30 & 40 \\
Speed (v) & $\mathrm{LT}^{-1}$ & $\mathrm{~m} / \mathrm{s}$ & 1 & 1 \\
Stress $(\sigma)$ & $\mathrm{ML}^{-1} \mathrm{~T}^{-2}$ & $\mathrm{MPa}$ & 1 & 1 \\
Strain $(\varepsilon)$ & & $\mathrm{s}$ & 1 & 1 \\
Time $(\mathrm{t})$ & $\mathrm{T}$ & & 30 & 40 \\
\hline
\end{tabular}

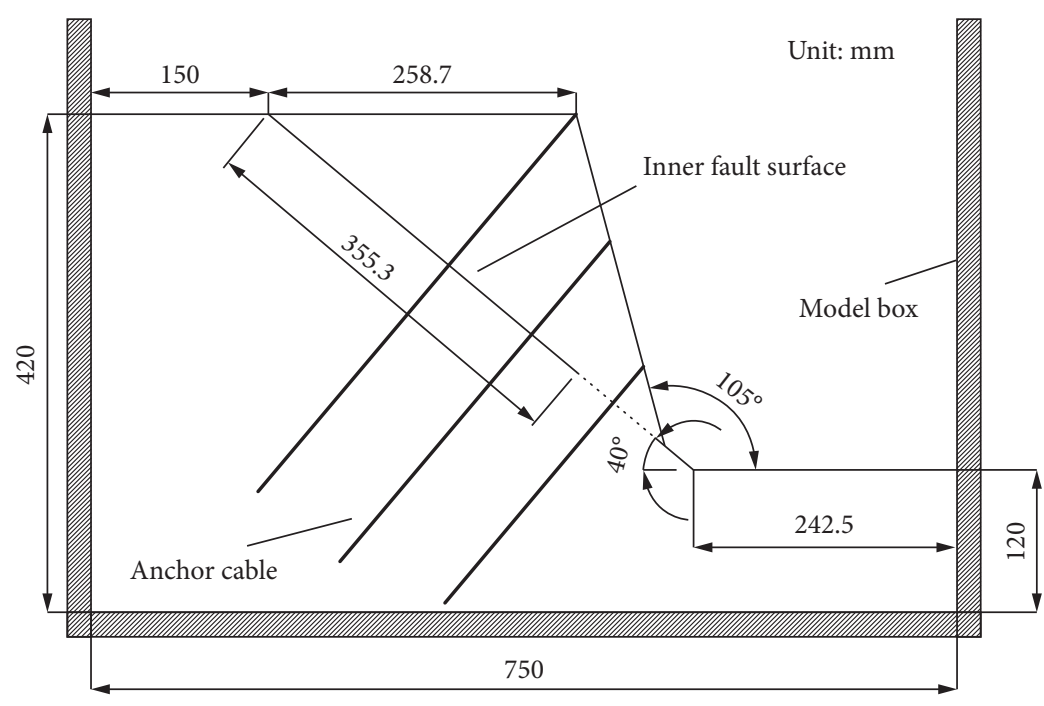

(a)

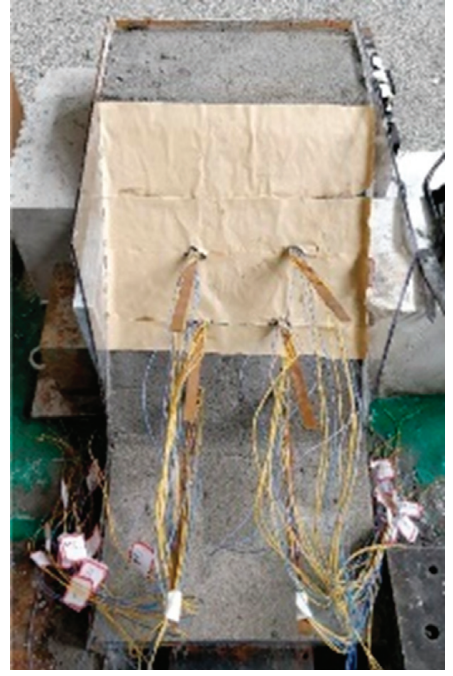

(b)

Figure 2: The model of centrifugal model test. (a) Schematic diagram. (b) The inner fault surface setting.

Therefore, in order to study the general regularity, the sinusoidal wave is selected as the input condition of the seismic load in this experiment.

At present, when analyzing the dynamic stability of the slope, the vertical earthquake is often ignored, and only the horizontal earthquake is considered. When considering the impact of the vertical earthquake, the common practice is to set the vertical peak acceleration as $1 / 3-2 / 3$ of the horizontal peak acceleration according to experience [24]. In this experiment, the vertical peak acceleration is set to be $1 / 2$ of the horizontal peak acceleration.

Li and Wang [25] found that due to the damping effect of the rock and soil media, the low-frequency part of the seismic wave attenuates much more slowly than the highfrequency part. The low-frequency part of the seismic wave can travel far, while the high-frequency part will attenuate rapidly. By studying the dynamic response of the slope under different frequency loads, Kontoe et al. [26] found that only when the acceleration frequency is between 0 and $2 \mathrm{~Hz}$ can the slope amplification coefficient be more obvious. This is consistent with the conventional belief that low-frequency waves have a greater impact on the rock and soil mass.
Therefore, the prototype load frequency set in this test is also between 0 and $2 \mathrm{~Hz}$.

The time history of the seismic wave prototype is $72 \mathrm{~s}$, and the cycle period is $0.56 \mathrm{~s}$. During the experiment, the earthquake motion in bidirection (horizontal and vertical) was applied to the model by using the shaking table on the centrifuge. The horizontal peak acceleration of excitation was adjusted to $7.5 \mathrm{~g}, 15 \mathrm{~g}, 10 \mathrm{~g}$, and $20 \mathrm{~g}$, respectively, as shown in Table 3. Correspondingly, the vertical peak acceleration was adjusted to $3.75 \mathrm{~g}, 7.5 \mathrm{~g}, 5 \mathrm{~g}$, and $10 \mathrm{~g}$ for each excitation. During the experiment, the time history of horizontal earthquake motion under one load condition (centrifuge acceleration-30 $\mathrm{g}$ and earthquake intensity-9) is shown in Figure 3.

2.4. Instruments and Measurements. The sensors including strain gauges and accelerometers were used in centrifuge modeling test. According to theoretical analysis, the anchor cable deformation is mainly distributed in the near-fault area under seismic load. The strain gauges were laid on anchor cables, and they were upwards numbered as SG1 to SG15, as shown in Figures 4(a) and 4(b). In order to monitor the 
TABLE 3: Detailed test condition.

\begin{tabular}{lcccc}
\hline Test number & $\begin{array}{c}\text { Acceleration of the } \\
\text { centrifuge }(\mathrm{g})\end{array}$ & $\begin{array}{c}\text { Horizontal peak } \\
\text { acceleration }(\mathrm{g})\end{array}$ & $\begin{array}{c}\text { Vertical peak } \\
\text { acceleration }(\mathrm{g})\end{array}$ & $\begin{array}{c}\text { Corresponding } \\
\text { earthquake intensity }\end{array}$ \\
\hline 1 & 30 & 7.5 & 3.75 & 8 \\
2 & 30 & 15 & 7.5 & 9 \\
3 & 40 & 10 & 5 & 8 \\
4 & 40 & 20 & 10 & 9 \\
\hline
\end{tabular}

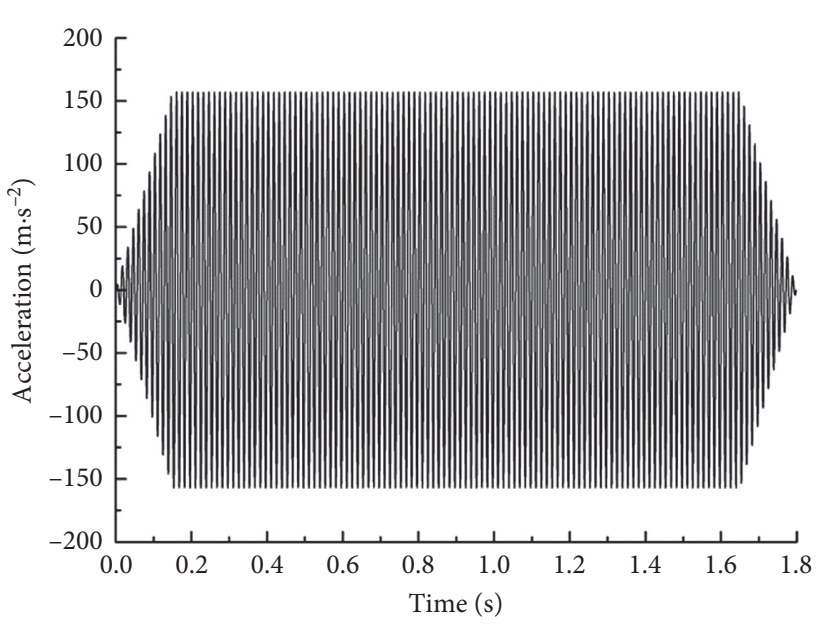

Figure 3: Schematic diagram of the input horizontal seismic wave under one load condition.

acceleration at different heights, horizontal accelerometers were laid at the bottom of the slope, the half-height section of the slope surface, and the top of the slope. The horizontal accelerometers were upwards numbered as A1 to A4, respectively. Additionally, the laser displacement sensor was set on the top of the slope, and it was numbered as LD0, as shown in Figure 4. The detailed parameters of the aforementioned various sensors are shown in Table 4.

2.5. Test Procedures. All the tests were divided into 3 steps. In the first step, centrifugal acceleration was increased to designed centrifugal acceleration. The next step was applied after deformation of the slope by the previous step had stabilized. In the second step, the seismic acceleration of test was loaded. Since the trial ended, turn off the centrifuge, and then proceed to the next experiment.

\section{Results and Discussion}

\subsection{Dynamic Response of the Slope}

3.1.1. Horizontal Acceleration Response. Figure 5 shows a time-domain diagram of slope acceleration for several points under different test conditions during the experiment. In order to analyze the data more intuitively, the acceleration data obtained from the experiment were restored to the prototype state by combining the similarity law relations under different experimental conditions. When the experimental condition is $30 \mathrm{~g}-8$, the horizontal acceleration response of points $\mathrm{A} 1, \mathrm{~A} 2$, and $\mathrm{A} 3$ is greater than that of point $\mathrm{A} 4$, and the maximum horizontal acceleration of $\mathrm{A} 1, \mathrm{~A} 2$, and
A3 is over $3 \mathrm{~m} / \mathrm{s}^{2}$. Similar experimental phenomena also occur under other experimental conditions.

Since the sine wave is applied during the experiment, the period of its original waveform is determined, so its spectrum is concentrated in one place. By analyzing the data of acceleration sensors at different positions under different test conditions, it is found that their spectral distribution is the same as the prototype wave, which is not described here.

3.1.2. Amplification of Acceleration of the Slope. In the related criteria of seismic design, seismic acceleration is the most important parameter to be considered in the design process. In the process of seismic loading, the acceleration distribution of the slope is usually expressed by the acceleration amplification factor (AAF), which is used to directly reflect the changes of the acceleration at different locations relative to the reference value. In this paper, the acceleration amplification factor (AAF) is used to represent the ratio of the peak ground acceleration (PGA) at a certain monitoring point (A1, A2, A3, and A4) of the slope to the maximum acceleration value output by the shaking table (A4) in the test process, so PGA and AAF can be defined as

$$
\begin{aligned}
\mathrm{PGA} & =\max |a(t)|, \\
\mathrm{AAF}_{A i} & =\frac{\mathrm{PGA}_{A i}}{\mathrm{PGA}_{A 4}}, \quad i=1,2,3,4,
\end{aligned}
$$

where $a(t)$ represents the measured accelerations in the time domain for each monitoring point.

In order to study the effect of the anchor cable on slope acceleration amplification, the AAF under four conditions was compared, as shown in Figure 6. The relative elevation $(h / H)$ is defined as the ratio of the height of the monitoring point $(h)$ to the total height $(H)$ of the model slope.

As seen in Figure 6, the AAF on the slope surface is always larger than 1.0. In the test process, the acceleration of the slope model has an obvious amplification effect. However, under 4 conditions, the AAF of the slope model presents a nonlinear dynamic response with increasing relative elevation. In the case of $30 \mathrm{~g}-8$ and $30 \mathrm{~g}-9$, the AAF first increased with the relative elevation, then remained unchanged or declined slightly, and finally increased at a lower rate compared with the first stage. In the case of $40 \mathrm{~g}-8$ and $40 \mathrm{~g}-9$, the AAF first increased with the relative elevation, then stayed the same or slightly decreased, and finally slightly increased. With the same acceleration, the AAF increased with the increase of seismic intensity, which was positively correlated. The nonlinear dynamic response of the AAF mentioned above can be explained as follows: 


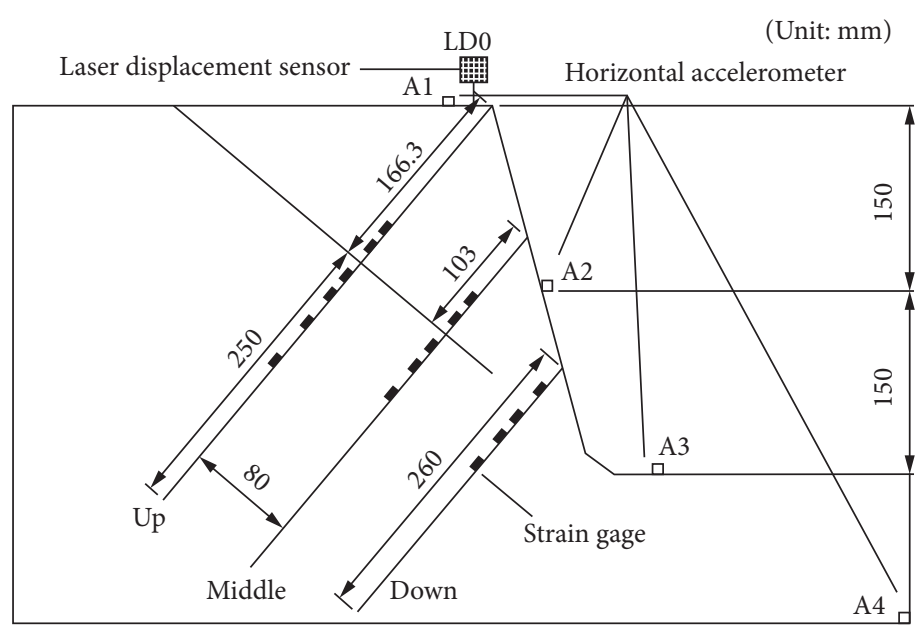

(a)

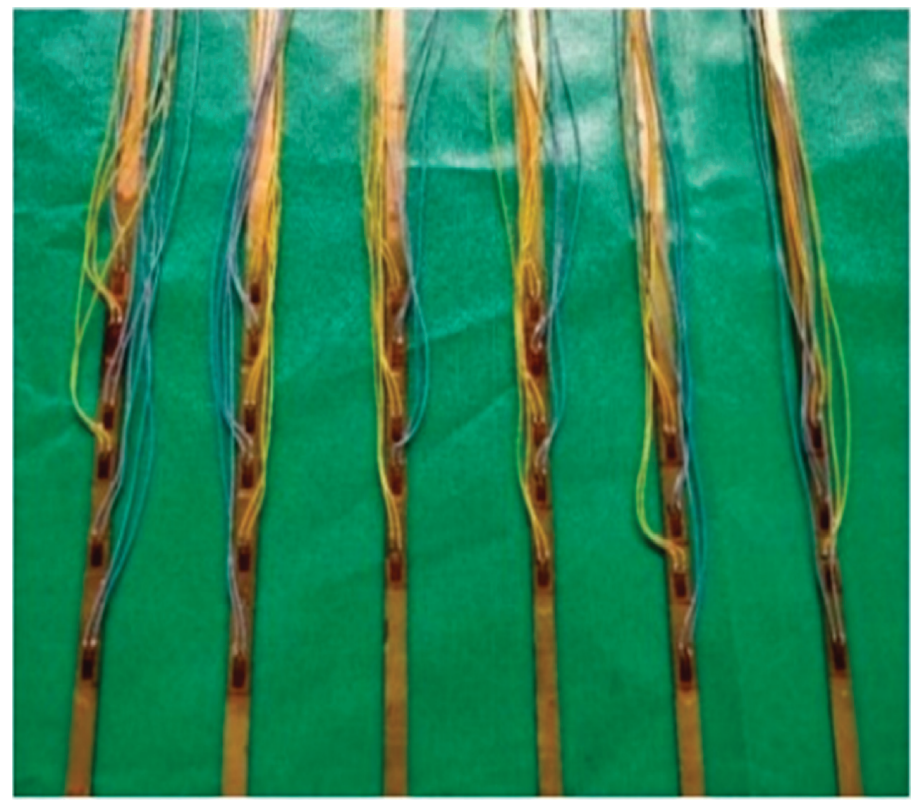

(c)

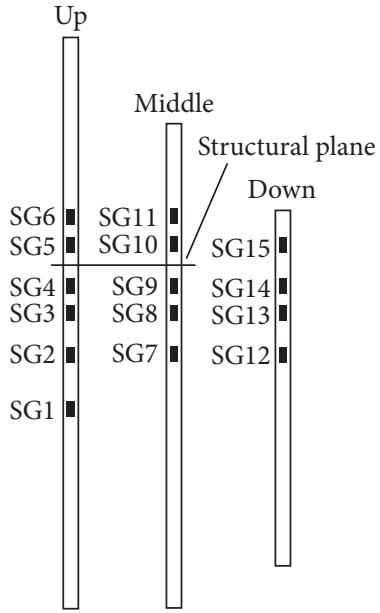

(b)

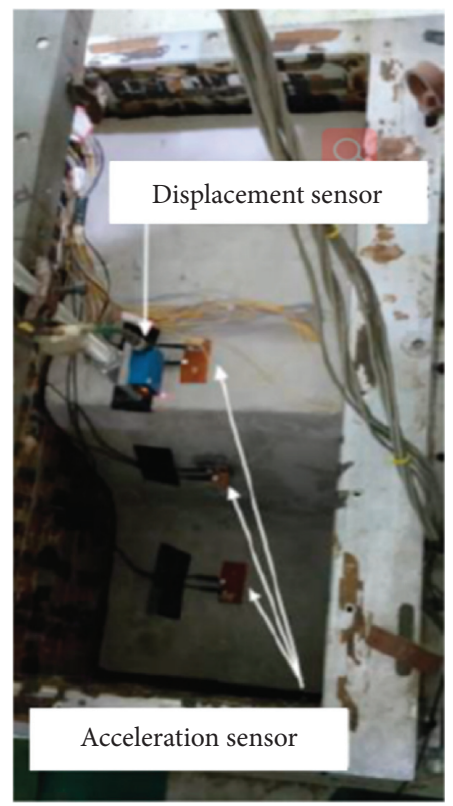

(d)

FIgURE 4: Schematic diagram and object diagram of the model sensor. (a) Schematic diagram of sensor setting. (b) Number of strain sensors. (c) Strain sensor installation. (d) Acceleration and displacement sensor settings.

TABLE 4: Detailed parameters of the sensors.

\begin{tabular}{lcccc}
\hline Sensor type & Model & Measuring range & Accuracy & Working temperature \\
\hline Acceleration & $3225 \mathrm{~F}$ (Dytran) & $\pm 4905 \mathrm{~m} / \mathrm{s}^{2}$ & $1.0 \mathrm{mV} / \mathrm{m} / \mathrm{s}^{2}$ & -51 to $121^{\circ} \mathrm{C}$ \\
Displacement & CP08MHT80(Wenglor) & $30-80 \mathrm{~mm}$ & $8 \mu \mathrm{m} /($ speed mode $) 12 \mu \mathrm{m}$ & -25 to $50^{\circ} \mathrm{C}$ \\
Strain sensor & & $2 \%$ & 2.08 & -10 to $60^{\circ} \mathrm{C}$ \\
\hline
\end{tabular}

(1) For general rock slopes (no structural plane and no anchor cable structure), the AAF is gradually increased when seismic waves are transmitted upward. In this experiment, the AAF of the A2 point is slightly lower than that of the A3 point. Some studies have shown that, for rock slopes with internal structural planes, the structural planes will dissipate more energy, which results in a decrease of the AAF.
In addition, considering the anchoring effect of the anchor cable, the AAF does not increase (or even decrease) at $\mathrm{A} 2$. For the $\mathrm{A} 1$ point, there is no structural plane between $\mathrm{A} 1$ and $\mathrm{A} 2$, and $\mathrm{AAF}_{\mathrm{A} 1}$ is increased compared with $\mathrm{AAF}_{\mathrm{A} 2}$ due to the increase of relative elevation. Due to the influence of the anchor cable, the increased speed and increment are decreased relative to $\mathrm{AAF}_{\mathrm{A} 4}-\mathrm{AAF}_{\mathrm{A} 3}$. 


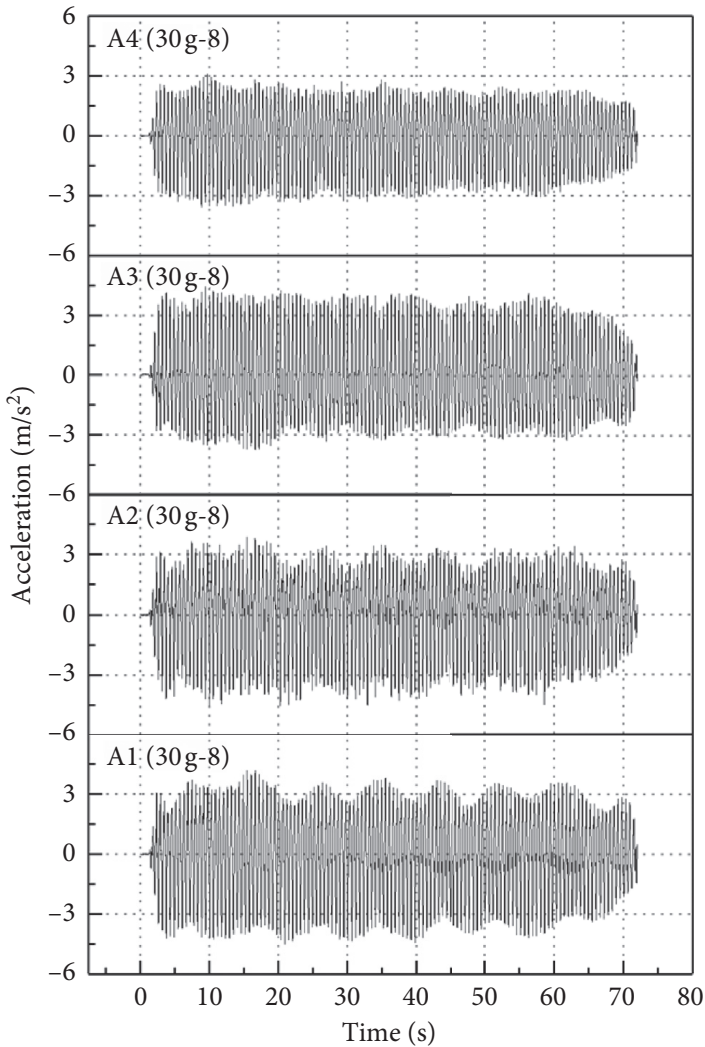

(a)

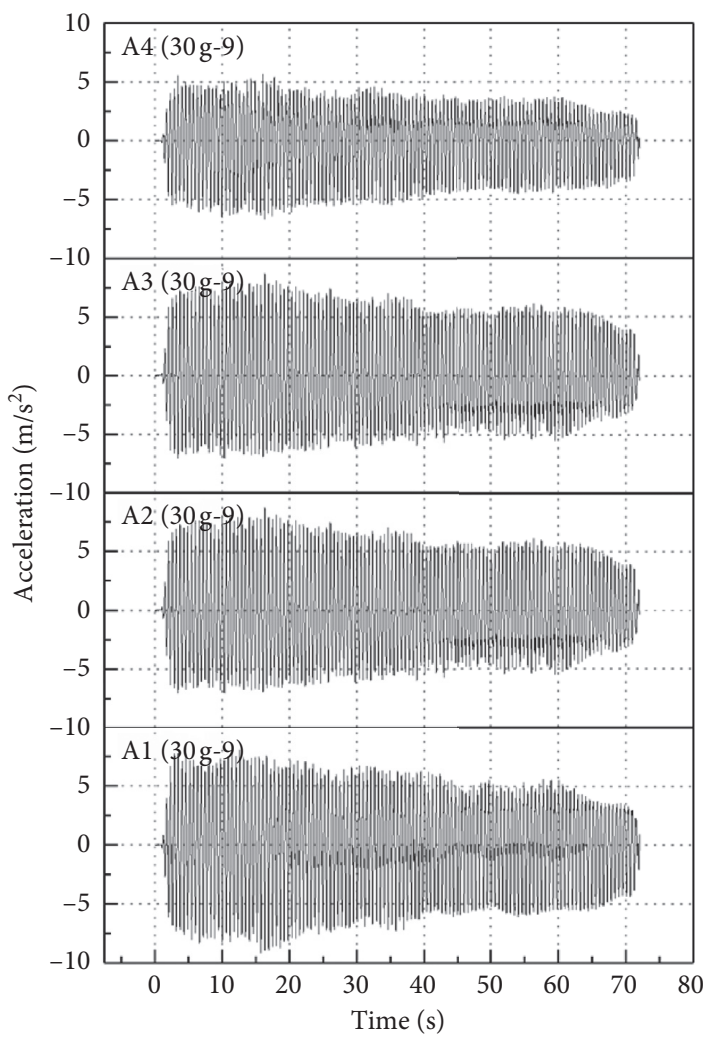

(c)

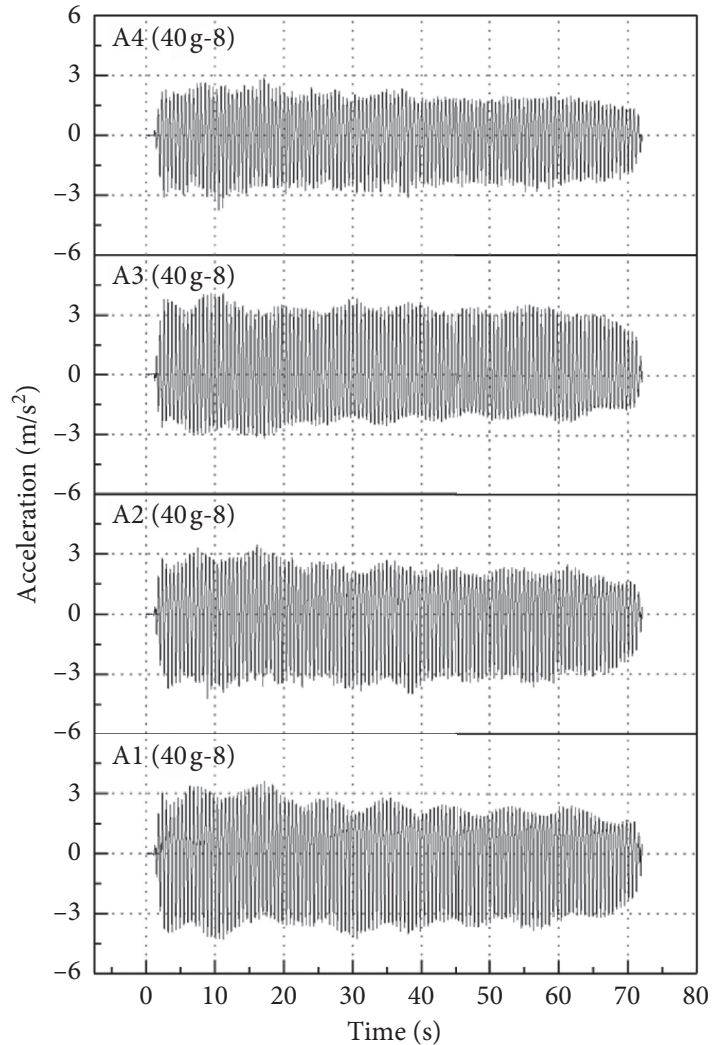

(b)

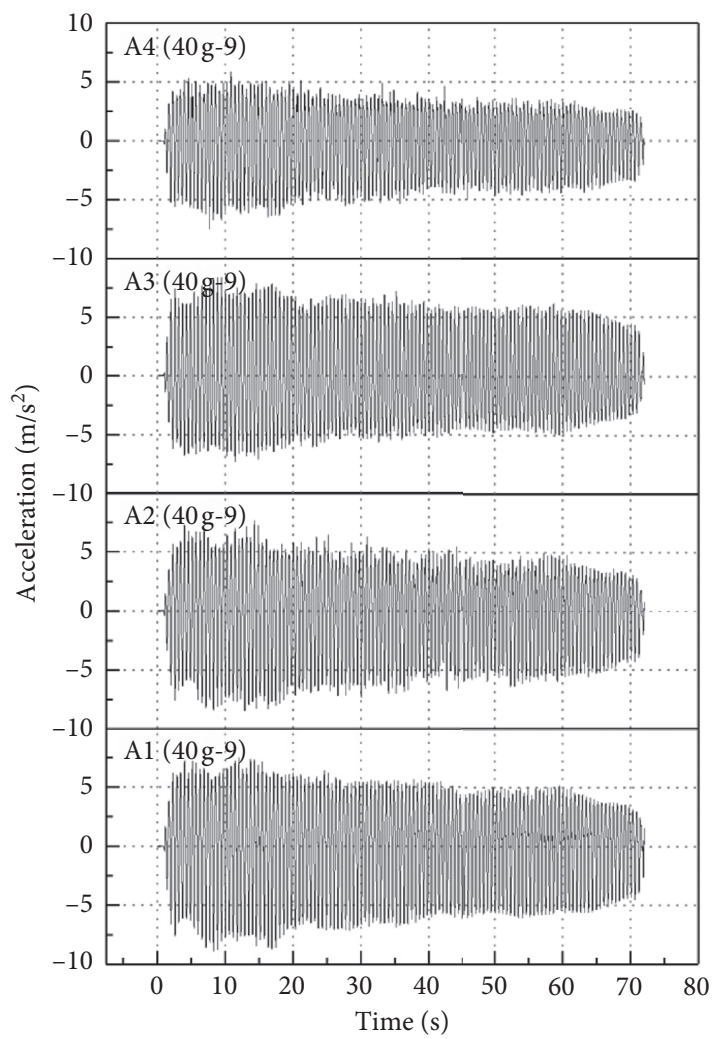

(d)

Figure 5: The time history of the horizontal acceleration response under different test conditions. (a) 30 g-8. (b) 40 g-8. (c) 30 g-9. (d) 40 g-9. 


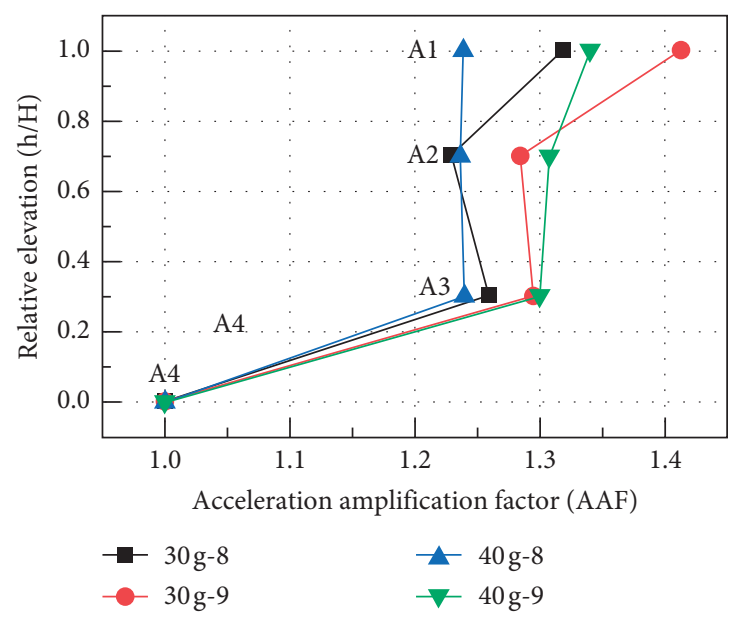

Figure 6: Acceleration amplification factors of the slope model.

(2) When the earthquake intensity increases, the amplitude of the seismic wave increases, and the energy of the wave increases correspondingly. The influence ratio of the structural plane and the anchor cable is relatively reduced. This explains why the AFF is greater at 9 degrees than it is at 8 degrees. And we can get the general law of the AAF: with the same conditions, the AAF is positively correlated with the elevation and seismic intensity.

3.1.3. Displacement Response of the Slope. The vertical displacement of the slope under different conditions is monitored by the displacement sensor in real time. The position of the laser displacement sensor is shown in Figure 4(a), and the detection data are shown in Figure 7.

With the application of the seismic load, the vertical displacements of the slope top increase gradually in an oscillatory manner. When the earthquake intensity is 9 degrees, the amplitude of periodic shock of the slope top is greater than 8 degrees. At the same time, after the end of the seismic load, the vertical displacement of the slope top does not return to the original position, and the slope has permanent deformation. The permanent deformation caused by the 9-degree earthquake is greater than that of the 8 -degree earthquake.

In order to further explore the displacement changes under different conditions, the displacement data were processed to obtain the slope-top displacement curve in Figure 8. It is observed that the displacement rises rapidly in the early stage of the earthquake and then rises slowly. After the seismic load, the vertical displacement of the slope decreases slightly.

When the earthquake intensity was 8 degrees, the final deformations were not significantly different under the conditions of $30 \mathrm{~g}$ and $40 \mathrm{~g}$. When the earthquake intensity was 9 degrees, the vertical displacement of the slope top under $40 \mathrm{~g}$ was significantly greater than that of $30 \mathrm{~g}$.

\subsection{Response Analysis of the Strain Gauge}

3.2.1. Strain Gauge Values Vary with Load. Centrifuge tests under 4 conditions (30 g-8, 30 g-9, 40 g-8, and 40 g-9) were conducted, and each test could obtain 15 groups of strain data. Figure 8 shows the measured data of the SG3 strain gauge on the upper anchor cable during the application of the 8-degree seismic load under $30 \mathrm{~g}$. As can be seen from Figure 9, the model will be affected by the centrifuge before loading, and the data show that there are continuous microseismic data before $0.5 \mathrm{~s}$. After $0.5 \mathrm{~s}$, when the seismic load is applied, strain increases rapidly in the initial stage and then increases slowly until the vibration stops. Compared with the amplitude of strain before loading, the amplitude of the strain vibration during loading is increased. After $2.3 \mathrm{~s}$, the seismic load stops, and the strain value shows a downward trend, but do not return to the initial level. This indicates that the strain gauge has some residual deformation.

By analyzing all the strain data, the larger the centrifugal acceleration and seismic intensity, the larger the amplitude of strain during loading and the residual deformation. It can be seen that the part deformation of the anchor cable is not permanent in the earthquake. After the seismic load, elasticplastic deformation occurs in the anchor cable inside the model, and some deformation remains. This is also consistent with the vertical displacement of the slope top.

3.2.2. Stress Analysis of the Anchor Cable. In the previous section, the data of 60 strain sensors of the cable during the test were obtained. In the centrifuge model, copper sheets are used to simulate the anchor cable. According to the stress-strain relationship $(\sigma=E \varepsilon)$, the stress data at different positions of the anchor cable can be obtained by combining the data of the strain sensor on the copper sheet and the mechanical parameters of the copper sheet.

According to symmetry, three unilateral anchor cables were selected for analysis and research under each working condition. Under different load conditions, the stress along each anchor cable at $1.5 \mathrm{~s}$ is shown in Figure 10. 


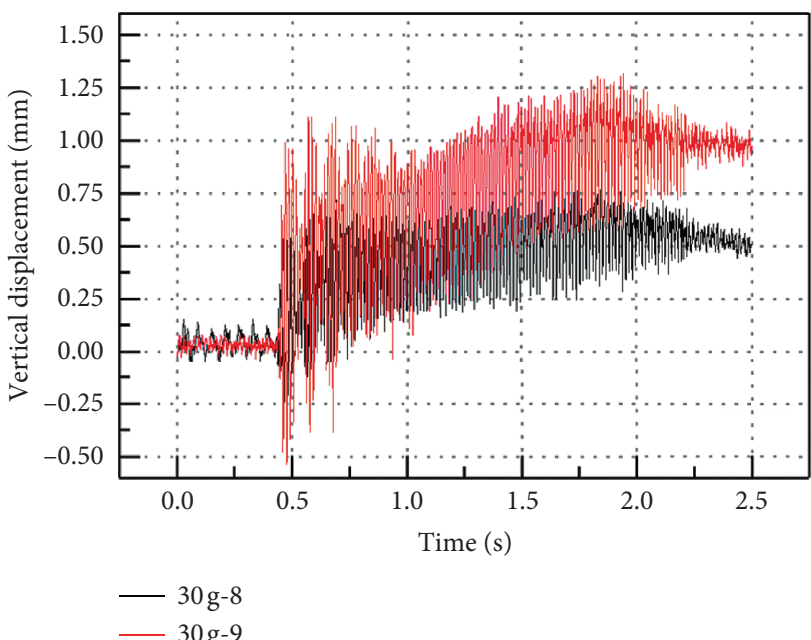

(a)

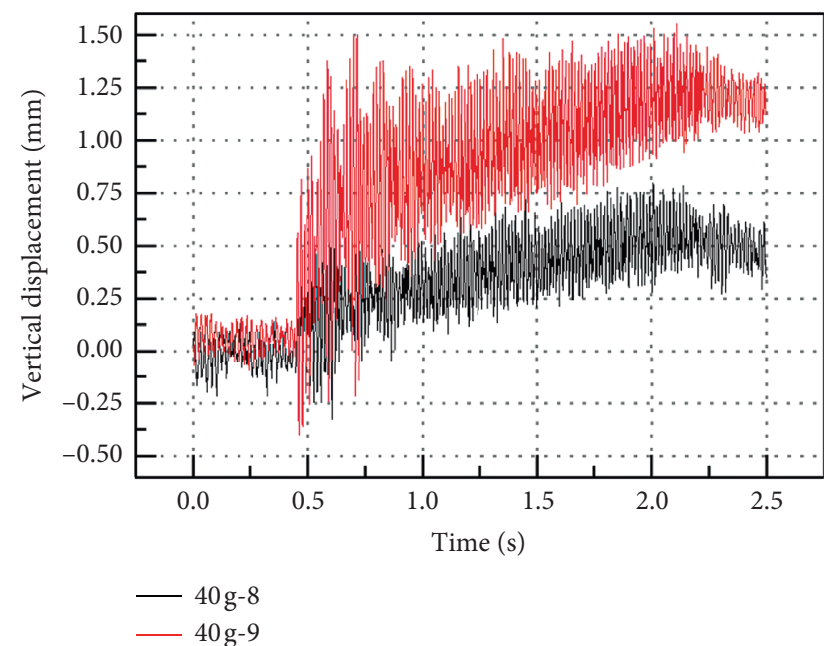

(b)

Figure 7: Vertical displacement curve of the slope top.
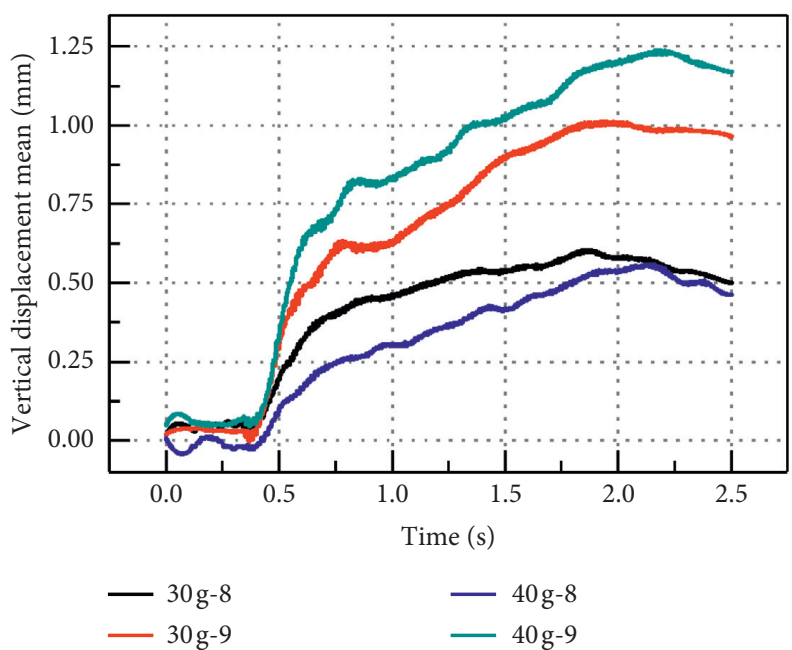

Figure 8: The displacement curve of the slope top.

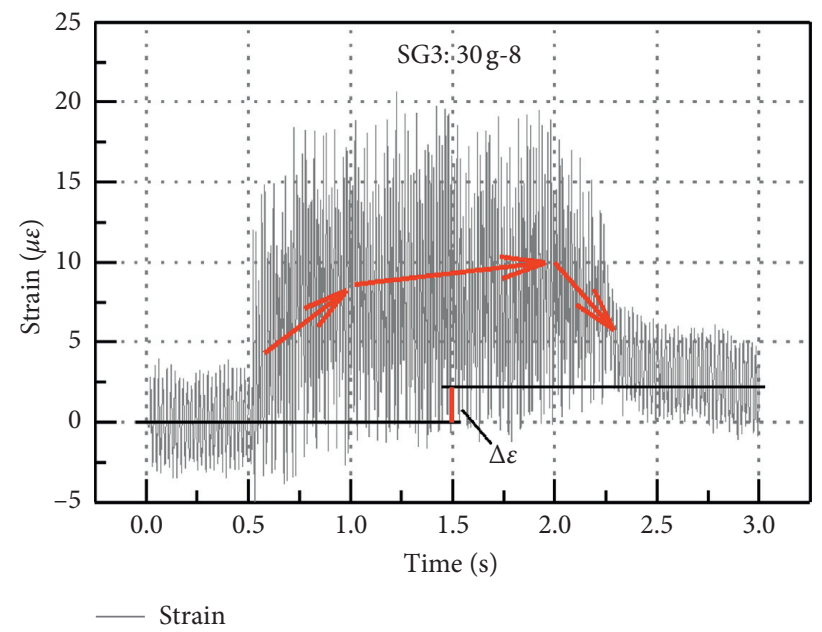

FIGURE 9: Strain curve of SG3 under 30 g-8. 


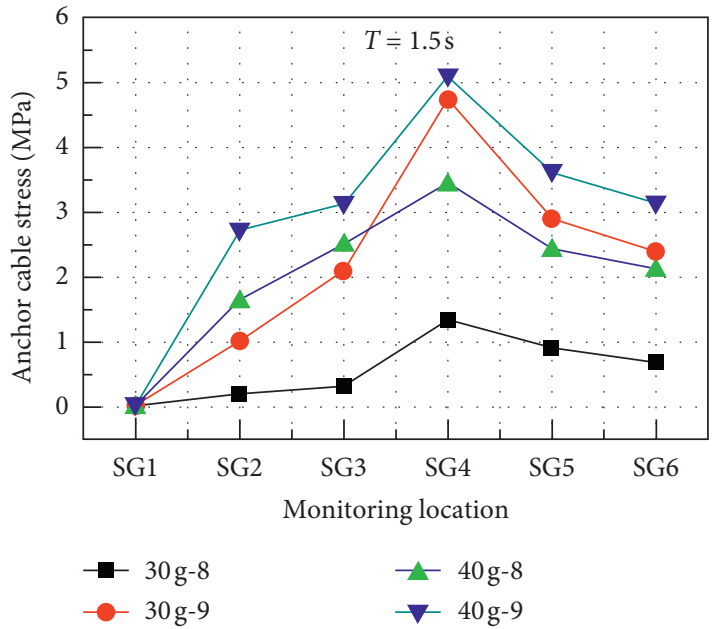

(a)

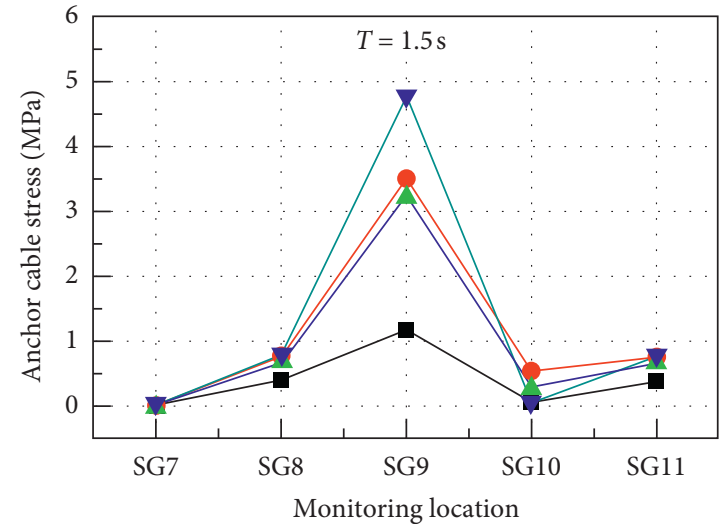

$-30 \mathrm{~g}-8$
$-30 \mathrm{~g}-9$
$-40 \mathrm{~g}-8$

$\neg$ 40g-9

(b)

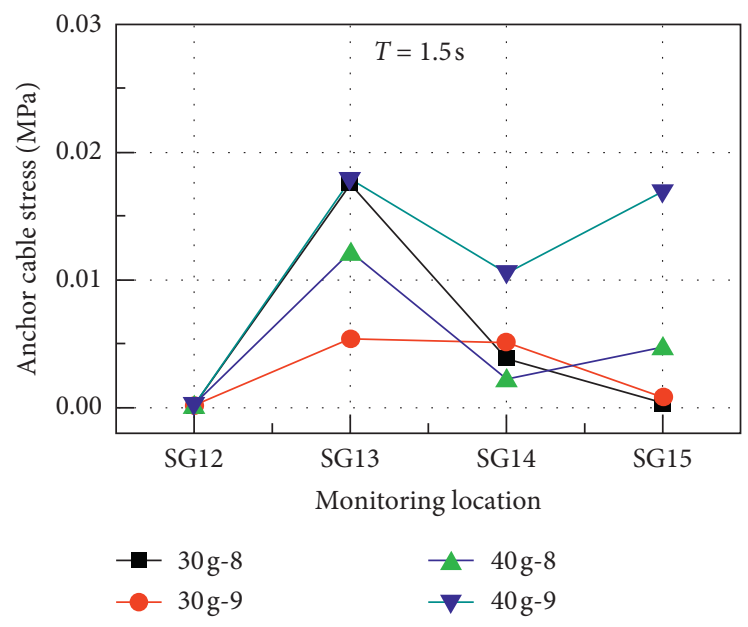

(c)

Figure 10: Stress along the anchor cable during load (1.5s). (a) Up anchor cable. (b) Middle anchor cable. (c) Down anchor cable.

In Figures 10(a) and 10(b), the stress of anchor cables in the experiment shows a sudden increase near the structural plane and decreases rapidly after it is far away from the structural plane. The maximum stress under different conditions is sorted from large to small as follows: $40 \mathrm{~g}-9$, $30 \mathrm{~g}-9,40 \mathrm{~g}-8$, and $30 \mathrm{~g}-8$. The range of stress increase is related to the intensity of the earthquake, but the expansion trend is not obvious. In Figure 10(c), the stress of the anchor cable is very small, and there is no obvious rule.

The above phenomenon shows that the deformation of the anchor cable near the structural plane of the slope is large. When the distance from the structural plane is further, the deformation of the anchor cable is smaller. The reasons for this phenomenon are as follows: (1) the up and middle anchor cables pass through the structural surface of the slope. When subjected to the seismic load, the movement of the slope body on both sides of the structural plane is inconsistent, resulting in the phenomenon of stress concentration in the anchor cable near the structural plane. (2) The down anchor cable does not pass through the structural plane, and relative deformation does not occur under the seismic load, resulting in stress changes which are very small and irregular.

\section{Conclusions}

In this paper, the centrifugal shaking table model test ( $30 \mathrm{~g}$ and $40 \mathrm{~g}$ ) for the rock slope with the structural plane was completed, and the acceleration response of the slope, the displacement of the slope top, and the stress response of the anchor cable were analyzed. Based on the test results, the conclusions are as follows:

(1) The acceleration of the slope model has an obvious amplification effect, and the AAF is always larger than 1.0. Due to the anchor cable structure, the AAF presents a nonlinear dynamic response with increasing relative elevation. Anchor cable can effectively reduce the acceleration amplification effect of the slope.

(2) During an earthquake, the slope top displacement increases rapidly at the initial stage, and then the 
slope decline speed decreases gradually and steadily. Its vibration waveform is in line with the seismic waveform. Seismic intensity has a great influence on the displacement of the slope top.

(3) After the vibration, the anchor cable will show residual deformation. The larger the centrifugal acceleration and seismic intensity, the larger the strain during loading and the residual deformation. It is necessary to consider the deformation of anchor cables under seismic load in the design stage.

(4) For the slope with a structural plane, the anchor cable near the structural plane is stressed greatly during the seismic action. In the design of the slope anchor cable structure, we should also consider the influence of the slope structure surface or potential sliding surface.

\section{Data Availability}

The experimental data used to support the findings of this study are available from the corresponding author upon request.

\section{Conflicts of Interest}

The authors declare that they have no conflicts of interest.

\section{Acknowledgments}

This research was supported by the National Key R\&D Program of China, grant number 2018YFC0407003, the Natural Science Foundation of China, grant number 51409283, and State Key Laboratory of Simulation and Regulation of River Basin Water Cycle.

\section{References}

[1] J. B. Hadley, Landslides and Related Phenomena Accompanging the Hebgen Lake Earthquake of August 17, 1959, US Government Printing Office, Washington, DC, USA, 1964.

[2] G. Plafker and G. Ericksen, "Nevados Huascaran avalanches, Peru," in Developments in Geotechnical Engineering, pp. 277-314, Elsevier, Amsterdam, Netherlands, 1978.

[3] S. G. Evans and A. L. Bent, The Las Colinas Landslide, Santa Tecla: A Highly Destructive Flowslide Triggered by the January 13, 2001, El Salvador Earthquake, Geological Society of America, Boulder, CO, USA, 2004.

[4] R. Huang, X. Pei, X. Fan, W. Zhang, S. Li, and B. Li, "The characteristics and failure mechanism of the largest landslide triggered by the Wenchuan earthquake, May 12, 2008, China," Landslides, vol. 9, no. 1, pp. 131-142, 2012.

[5] R. Huang and X. Fan, "The landslide story," Nature Geoscience, vol. 6, no. 5, pp. 325-326, 2013.

[6] Y.-1. Lin, W.-m. Leng, G.-l. Yang, L. Li, and J.-S. Yang, "Seismic response of embankment slopes with different reinforcing measures in shaking table tests," Natural Hazards, vol. 76, no. 2, pp. 791-810, 2015.

[7] B. Has and T. Nozaki, "Role of geological structure in the occurrence of earthquake-induced landslides, the case of the 2007 Mid-Niigata offshore earthquake, Japan," Engineering Geology, vol. 182, pp. 25-36, 2014.
[8] S. Qi, Q. Xu, H. Lan, B. Zhang, and J. Liu, "Spatial distribution analysis of landslides triggered by 2008.5.12 Wenchuan earthquake, China," Engineering Geology, vol. 116, no. 1-2, pp. 95-108, 2010.

[9] G. Fan, J. Zhang, J. Wu, and K. Yan, "Dynamic response and dynamic failure mode of a weak intercalated rock slope using a shaking table," Rock Mechanics and Rock Engineering, vol. 49, no. 8, pp. 3243-3256, 2016.

[10] C. Massey, F. Della Pasqua, C. Holden et al., "Rock slope response to strong earthquake shaking," Landslides, vol. 14, no. 1, pp. 249-268, 2017.

[11] Z. Zhang, T. Wang, S. Wu, H. Tang, and C. Liang, "Seismic performance of loess-mudstone slope by centrifuge tests," Bulletin of Engineering Geology and the Environment, vol. 76, no. 2, pp. 671-679, 2017.

[12] Z. Zhang, T. Wang, S. Wu, H. Tang, and C. Liang, "Seismic performance of loess-mudstone slope in Tianshui-centrifuge model tests and numerical analysis," Engineering Geology, vol. 222, pp. 225-235, 2017.

[13] B. L. Kutter, T. J. Carey, T. Hashimoto et al., "LEAP-GWU2015 experiment specifications, results, and comparisons," Soil Dynamics \& Earthquake Engineering, vol. 113, 2017.

[14] X. Li, H. Tang, C. Xiong, J. Wartman, and Y. Yin, "Dynamic centrifuge modelling tests for toppling rock slopes," in Engineering Geology for Society and Territory, Springer, Berlin, Germany, 2015.

[15] M. Tricarico, G. S. P. Madabhushi, and S. Aversa, "Centrifuge modelling of flexible retaining walls subjected to dynamic loading," Soil Dynamics and Earthquake Engineering, vol. 88, pp. 297-306, 2016.

[16] A. J. Brennan, N. I. Thusyanthan, and S. P. Madabhushi, "Evaluation of shear modulus and damping in dynamic centrifuge tests," Journal of Geotechnical and Geoenvironmental Engineering, vol. 131, no. 12, pp. 1488-1497, 2005.

[17] A. Mortazavi and F. Tabatabaei Alavi, "A numerical study of the behavior of fully grouted rockbolts under dynamic loading," Soil Dynamics and Earthquake Engineering, vol. 54, no. 11, pp. 66-72, 2013.

[18] H. Zhou, M. Xiao, and J. Chen, "Analysis of a numerical simulation method of fully grouted and anti-seismic support bolts in underground geotechnical engineering," Computers and Geotechnics, vol. 76, pp. 61-74, 2016.

[19] Y.-1. Lin, G.-l. Yang, X. Yang, L.-h. Zhao, Q. Shen, and M.-m. Qiu, "Response of gravity retaining wall with anchoring frame beam supporting a steep rock slope subjected to earthquake loading," Soil Dynamics and Earthquake Engineering, vol. 92, pp. 633-649, 2017.

[20] S. Nakamoto, N. Iwasa, and J. Takemura, "Effects of nails and facing plates on seismic slope response and failure," Géotechnique Letters, vol. 7, no. 2, pp. 136-145, 2017.

[21] N. Srilatha, G. M. Latha, and C. G. Puttappa, "Seismic response of soil slopes in shaking table tests: effect of type and quantity of reinforcement," International Journal of Geosynthetics and Ground Engineering, vol. 2, no. 4, p. 33, 2016.

[22] H. L. Langhaar, Dimensional Analysis and Theory of Models, John Wiley, Hoboken, NJ, USA, 1951.

[23] R. N. Taylor, Geotechnical Centrifuge Technology, Blackie Academic and Professional, London, UK, 2005.

[24] L. D. Yang, J. I. Qian-Qian, Y. L. Zheng, and C. Yang, "Study on design of test box in shaking table test for subway station structure in soft soil," Chinese Jounal of Geotechnical Engineering, vol. 26, no. 1, pp. 75-78, 2004. 
[25] J. G. Li and D. Wang, "Analysis of statistic characteristics of peak ratios in vertical and horizontal ground motion acceleration," Journal of Seismological Research, vol. 33, no. 2, pp. 195-199, 2010.

[26] S. Kontoe, L. Zdravkovic, and D. M. Potts, "An assessment of time integration schemes for dynamic geotechnical problems," Computers and Geotechnics, vol. 35, no. 2, pp. 253-264, 2008. 